\title{
Sustainable Development and Corporate Communication in Global Markets"
}

\author{
Daniela M. Salvioni ${ }^{* *}$ Luisa Bosetti ${ }^{* * *}$
}

\begin{abstract}
The increasing importance of sustainability for corporate governance involves paying stronger attention to the principles and values dominating internal and external relationships; moreover, it requires innovation in the internal processes of behavioural orientation, as well as in external communication. In particular, the multidimensionality of responsibilities, goals and results has determined progressive changes in corporate communication.

This article aims at investigating the linkage among sustainability, stakeholder relations management and effectiveness of corporate communication. More exactly, the article intends to highlight the transition from a period of disorderly enlargement of corporate communication to a phase characterised by a new concept of integrated reporting. Integrated reporting is based on broadly shared principles and it encourages the development of a stand-alone document concerning governance, financial and socio-environmental performance.
\end{abstract}

Keywords: Sustainable Development; Global Responsibility; Corporate Governance; Corporate Communication; Integrated Reporting

\section{Responsibility and Corporate Communication}

Transparency is a requirement for good corporate governance and should represent the dominant quality of all the firm's activities. In external relationships, transparency should find expression in communication processes.

For a long time corporate governance has aimed at satisfying shareholder expectations concerning profit maximisation, sometimes with differences among sub-categories of stockholders according to their importance. In this regard, the financial communication consisting in the financial statements and, if necessary, the consolidated ones used to be considered essential (Salvioni 1990).

\footnotetext{
* The Authors: D. M. Salvioni $§ \S 1,5$, L. Bosetti $\S \S 2,3,4$

${ }^{* *}$ Full Professor of Business Administration, University of Brescia (salvioni@eco.unibs.it)

*** Assistant Professor in Business Administration, University of Brescia (bosetti@eco.unibs.it)

Edited by: ISTEI - University of Milan-Bicocca

ISSN: 1593-0319

Salvioni Daniela M., Bosetti Luisa (2014) Sustainable Development and Corporate Communication in Global Markets, Symphonya. Emerging Issues in Management (symphonya.unimib.it), n. 1, pp. 1-19
}

http://dx.doi.org/10.4468/2014.1.03salvioni.bosetti 
In the last quarter of the twentieth century, firms started to recognise the value of interacting with all major stakeholders; since then, they have adopted a broader concept of responsibility, which stresses the strong interdependencies among economic, social and environmental goals. Such a change has taken place slowly and differently in diverse countries and firms and it has involved modifications in the governance approach. Moreover, it has also emphasised the importance of corporate communication and it has promoted the most adequate contents and ways of dissemination to meet stakeholders' needs of information and evaluation. To this purpose, the firm's communication - traditionally based on the financial disclosure - has been enriched over the years, in order to improve transparency on corporate governance by means of new types of documents, such as the corporate governance statement, the directors and chief officers' remuneration report, the social report, the environmental report, the sustainability report, and the report on intangible assets. Furthermore, the information contained in these documents have become more and more detailed, and sometimes abounding and overlapping too.

The enlargement of information required for a more transparent governance has been accompanied by new methods for content dissemination, connected to the use of more and more appropriate tools to facilitate both the access to the information and the timeliness. ICT development has made the communication more effective, thanks to the reduction of costs and time for preparing and disseminating information; moreover, ICT has knocked down space barriers, accelerating the fulfilment of information symmetry and international uniformity.

The transformations in the socio-economic background during this century (progressive diffusion of ICT, globalisation, social inequality, climate change, corruption, etc.) have inspired an increasing interest in an advanced concept of sustainable development as a guiding condition for all the players operating in the economic system.

Global markets call for new and complex processes of corporate governance, aimed at a generalised recovery of effectiveness in relation to the growing dynamism and the progressively rising complexity of the firm-environment relationships (Brondoni 2006). In this regard, sustainable development is a prominent issue, whose implementation involves a proper orientation of governance policies, the sharing of ethical principles and values within the corporate network and the adoption of effective processes of corporate communication.

The active participation to a more efficient, environment-oriented and competitive economy determines huge modifications in the complexity of the relations between the firm and its significant stakeholders. Meanwhile, the diffusion of knowledge stresses the possibility for the latter to be informed and to carry out comparisons.

Nowadays, successful firms are expected to adopt, maintain and strengthen governance systems that should comply with the international best practices and should permit to manage the complexity of the business and the major conditions for sustainable development (Perrini, Vurro 2010). In this sense, the effectiveness of governance is mainly influenced by the assumption of policies that aim at emphasising the principles of global responsibility, positive and equitable interaction with the stakeholders and environmental protection. 
The advent of an integrated concept of responsibility, based on the effectiveness of stakeholder relations, has involved a rethinking of corporate communication, in order to determine transparent and internationally accepted models. In this regard, the so-called Integrated Reporting has taken hold.

An integrated report is a document by which a firm informs all the stakeholders in a clear, truthful and comparable way about how it has accomplished its responsibility and about the results it has obtained.

According to basic conditions of firm's unity and continuity, a stand-alone integrated report provides information on governance and financial, social and environmental performance. In other words, the document should permit all interested stakeholders to know who and how has managed the responsibility, which results have been achieved and which goals have been established from a sustainability perspective.

\section{Integrated Reporting}

In 1987, the United Nations' Brundtland Commission published a famous report coining the expression 'sustainable development'. Since then, sustainable development has been considered as a model of growth that makes firms responsible for their own profitable continuity, but also for a reasonable use of natural resources to guarantee environmental conservation in behalf of future generations ${ }^{1}$. The traditional definition of sustainable development, reaffirmed in 2002 UN World Summit in Johannesburg, stresses the integration of three pillars: economic growth, social inclusion and environmental protection. A broader concept, based on Agenda 21 and 2005 Unesco Convention, also includes cultural diversity as the fourth pillar of sustainable development, which should take place on local, regional, national and global level.

The respect of sustainability principles involves modifications in corporate governance and in both internal and external communication. Internal communication should be reorganised to support behaviour orientation, by explicating in a clear way the goals pursued by the firm according to logics of integrated performance and global responsibility (Salvioni 2003; Salvioni, Bosetti 2009). External communication should inform in a transparent and reliable way about firm's governance: such a disclosure should enhance the stakeholders' trust in the firm's ability to satisfy their needs and should improve their assent to the firm's mission, strategies and operations.

The debate on sustainable development involves a new necessity of accountability. Evidently, financial reporting is no longer sufficient to guarantee full transparency on firm governance and fulfilment of responsibilities towards different categories of stakeholders.

Some attempts to enlarge the contents of external disclosure have taken place since the Seventies, when labour and ecological awareness started to increase in the business landscape. For instance, the American consultants ABT Boston released a pioneering model of social and financial accounting and reporting, which tried to integrate the monetary value of positive and negative externalities into the financial statements (Epstein et al. 1976). In the meantime, in Europe, a German study group on social reporting suggested the publication of a stand-alone 
document, separate from the mandatory financial one but reconciled to it through a section focused on economic indicators (Dierkes 1974).

However, the diffusion of social and environmental reporting has been limited for a long time, probably due to the consultants and auditors' scarce knowledge of such topics and the lack of guidelines and standards. Moreover, the US Securities and Exchange Commission (SEC) had discouraged the insertion of social and environmental information in listed companies' annual reports, not to overload the documents. The SEC had also underlined that the annual report was typically addressed to the shareholders, whose interest in the social and environmental issues was usually low.

After a phase of limited interest in non-financial disclosure during the Eighties, the debate has revived since the Nineties, thanks also to the significant attention of the United Nations and the European Union for sustainable development and corporate responsibility ${ }^{2}$.

This renewed interest has emerged in several proposals for improving nonfinancial communication. Procedure and content standards, applicable on a voluntary basis, have been published by international organisations, such as the Copenhagen Centre (promoter of the AccountAbility 1000 Standards) and the Coalition for Environmentally Responsible Economies (which originated the Global Reporting Initiative - GRI). Since late Nineties, GBS association has relevantly contributed to the diffusion of social reporting in Italy ${ }^{3}$; probably, it has produced better results than a 2002 Ministry of Labour's project for the introduction of a social statement in firms' communication ${ }^{4}$.

All the above-mentioned initiatives are based on standards and guidelines that suggest disseminating social and environmental information by means of standalone documents, usually published on an annual basis but separate from the mandatory financial reports. This situation has determined the divulgation of two or more distinct reports, particularly by listed companies that must satisfy the information needs of different stakeholders (including shareholders, banks and other financial lenders, employees, trade unions, credit rating agencies, suppliers, customers, tax authorities, and the civil society).

Today, some companies divulge a financial report, a social report, an intellectual capital report, an environmental report, a corporate governance statement and a remuneration statement. In other cases a sustainability report, separate from the financial one, comprises a description of corporate governance, together with narrative and quantitative sections on economic, social and environmental topics. A presentation of the firm is often replicated in more documents, whereas the details on corporate governance and financial, social and environmental performance must be collected from several reports. Hence, preparing the information becomes more expensive, even if costs and time for divulgation have decreased.

The increasing cross-connections between economic and socio-environmental requirements for corporate effectiveness have recently stimulated the research on integrated reporting. An integrated report could be used as a valid tool of stakeholder relations management and should emphasise the linkage among:

- the resources provided by the stakeholders (e.g. financial capital, goods and natural resources, human and intellectual capital, social relationships, and market relationships); 
- the activities carried out by the firm to satisfy different needs, according to its mission and vision and considering opportunities and threats; and

- the firm performance, which measures the ability to meet internal and external expectations and to durably grow, in full respect of sustainability and global responsibility principles.

Since the beginning of this century, several initiatives and contributions from academics, research groups, regulatory commissions and policy makers have highlighted the need for integrated reporting and encouraged the debate all over the world (Jensen, Berg 2011). In this regard, the EU institutions have played a leading role since the issue of Directive 2003/51/EC on the annual and consolidate accounts ("Modernisation Directive"). Indeed, the Directive states that «the information should not be restricted to the financial aspects of the company's business. It is expected that, where appropriate, this should lead to an analysis of environmental and social aspects necessary for an understanding of the company's development, performance or position». The European Commission also hosted a series of workshops on the disclosure of environmental, social and governance (ESG) information between September 2009 and February 2010. Then, it released a proposal in April 2013 for amending the Fourth Directive and the Seventh Directive, in order to require certain large companies «to disclose a statement in their Annual Report including material information relating to at least environmental, social, and employee-related matters, respect of human rights, anticorruption and bribery aspects».

Many countries have recently introduced laws, regulations, listing requirements and recommendations concerning the integration of financial and non-financial reporting (Eccles, Krzus 2010; Krzus 2011; Eccles, Serafeim 2011) (Table 1).

Table 1: Initiatives to promote integrating reporting

\begin{tabular}{|c|c|c|}
\hline Year & Country & Initiative \\
\hline 2006 & United Kingdom & $\begin{array}{l}\text { Launch of the Accounting for Sustainability Project. The project } \\
\text { was completed in } 2009 \text { with the issue of a framework } \\
\text { recommending a clear and concise presentation of sustainability } \\
\text { information in the annual report. }\end{array}$ \\
\hline 2007 & Malaysia & $\begin{array}{l}\text { It was announced that all listed companies would be required to } \\
\text { publish CSR information within their annual reports. }\end{array}$ \\
\hline 2007 & Sweden & $\begin{array}{l}\text { All state-owned firms had to publish sustainability reports in } \\
\text { accordance with the GRI Guidelines. }\end{array}$ \\
\hline 2008 & China & $\begin{array}{l}\text { The publication of CSR information by state-owned companies } \\
\text { was encouraged. }\end{array}$ \\
\hline 2008 & Argentina & $\begin{array}{l}\text { A law required large listed companies to produce a GRI } \\
\text { sustainability report. }\end{array}$ \\
\hline 2009 & South Africa & $\begin{array}{l}\text { The listing rules based on the King Code of Governance imposed } \\
\text { all listed companies to issue an integrated report, beginning in } \\
2010 \text {, or to explain the reasons why they do not so. }\end{array}$ \\
\hline 2009 & Denmark & $\begin{array}{l}\text { Large firms, state-owned companies and investors were required } \\
\text { to describe their corporate responsibility policies and practices in } \\
\text { the annual report. }\end{array}$ \\
\hline 2010 & United States & $\begin{array}{l}\text { The SEC issued an interpretative guidance in order to clarify how } \\
\text { to disclose on climate change and greenhouse gas emissions. }\end{array}$ \\
\hline 2010 & France & Grenelle II Act imposed large listed and private companies to \\
\hline
\end{tabular}




\begin{tabular}{|l|l|l|l|}
\hline & $\begin{array}{l}\text { provide non-financial information in their annual report, } \\
\text { beginning in 2012. }\end{array}$
\end{tabular}

Integrated reporting is currently encouraged by the valuable activity of the International Integrated Reporting Council (hereafter, the IIRC), whose foundation was initially discussed in 2009, during a meeting of the Prince of Wales's Accounting for Sustainability Project.

\section{The IIRC Framework}

The IIRC is a global coalition established in 2010, which joins regulators, investors, companies, standard setters, accountants and NGOs sharing a new concept of integrated reporting that has been tried and tested for some years now by the participants to two Pilot Programmes (Table 2). The IIRC aims at contributing to a sustainable global economy by encouraging the spread of "integrating thinking". That means understanding and acquainting providers of resources with the connections among the most significant components of the firm and the linkage with external stakeholders.

\section{Table 2: The IIRC Pilot Programmes}

\section{Pilot Programme Business Network}

Launched in 2011, the Programme includes about 100 firms from different countries and industries, such as AB Volvo (Sweden), Atlantia (Italy), Danone (France), Deutsche Bank (Germany), Enel (Italy), Eni (Italy), HSBC Holdings (UK), Hyundai Engineering \& Construction (South Korea), Marks and Spencer Group (UK), Natura (Brazil), New Zealand Post (New Zealand), Novo Nordisk (Denmark), Petrobras (Brazil), Repsol (Spain), Sap (Germany), Snam (Italy), the State Atomic Energy Corporation Rosatom (Russia), Tata Steel (India), Telefónica (Spain), Terna (Italy), Coca Cola (USA), Unilever (UK), and Vancity (Canada). The Programme also includes representatives of accounting consultants, such as the Association of Chartered Certified Accountants (UK), the Chartered Institute of Management Accountants (UK), and CNDCEC (Italy), as well as some member firms of Deloitte, KPMG, Ernst \& Young and PWC networks.

Pilot Programme Investor Network

Launched in 2012, the Programme comprises over 30 global investor organisations, such as AQAL Investing (Germany), APG (Netherlands), CFA Institute (USA), the European Federation of Financial Analysts Societies (with headquarters in Frankfurt, Germany), Element (South Africa), the Financial Services Council (Australia), Goldman Sachs (UK), Nissay Asset Management Corporation (Japan), Railways Pension Trustee Company Limited (UK), Rockefeller Financial (USA), and Skandinaviska Enskilda Banken (Sweden).

On 9 December 2013 the IIRC issued its International $\langle I R\rangle$ Framework (hereafter, the Framework), a guide on integrated reporting (hereafter, <IR>) incorporating the feedbacks from a three-month public consultation based on a draft released on 16 April.

The Framework is composed of four chapters and it is primarily intended for application by private firms of any size. However, it can be adapted for the use by public and not-for-profit organisations too. 
Chapter 1 (Using the Framework) gives an overview of the integrated report, which is defined as «a concise communication about how an organization's strategy, governance, performance and prospects, in the context of its external environment, lead to the creation of value over the short, medium and long term».

$<\mathrm{IR}>$ is intended to explain how different factors interact for the creation of value over time. Since such factors are usually discussed in separate documents, <IR> should demonstrate the connectivity of information divulged by the organisation. In this regard, an integrated report can either be an additional, stand-alone document or form a specific chapter of other corporate communications (e.g. financial statements, sustainability, social and environmental reports, investor presentations and other analyses for selected stakeholders).

In the IIRC's intention, the providers of financial capital, namely existing and potential equity and debt holders, including all creditors and fund managers, should be the main users of an integrated report. However, the document can also satisfy the information needs of all other stakeholders (employees, customers, suppliers, business partners, local communities, regulators and policy-makers).

The Framework promotes a transparent disclosure and suggests some reporting principles to balance flexibility and prescription, even if cases of non-compliance must be motivated. Nevertheless, the IIRC does not impose either a format for the integrated report or a set of key performance indicators (KPIs). On the contrary, the IIRC accepts any type of measurement and KPIs the organisation determines in compliance with mandatory rules on external communication and voluntary reporting guidelines.

The quality of the report improves when it also includes a description of the role played by corporate governance board members within the <IR> process. In particular, the integrated report should provide a statement of responsibility signed by the board members.

Chapter 2 introduces the Fundamental concepts of value creation over time. The IIRC helps the firms improve their transparency and accountability offering a guide for demonstrating the interdependencies among different elements: the use of capitals; the firm's governance and ability to meet the stakeholders' legitimate needs and expectations; the business model and the strategy, in respect to risks and opportunities; finally, the impact on the resources over time.

According to its mission and vision, any organisation interacts with internal and external stakeholders to create value through the combination of capitals, which belong partly to the organisation itself and partly to others, such as a local community or a national government. Hence, a brief description of the modifications in capitals originated by business is essential for an effective integrated report. In this regard, the Framework classifies the capitals into six categories:

- financial capital, including the money collected through financing or generated by investments;

- manufactured capital, referring to the firm's tangible assets (e.g. buildings and equipment), but also to the infrastructure (e.g. roads) which usually belongs to external parties, such as the State;

- intellectual capital, comprising the intellectual property of patents, copyrights, software, etc., and the organisational capital based on knowledge and internal procedures; 
- human capital, composed of employees' competencies, capabilities, experience, motivation, loyalty to the mission and spirit of innovation;

- social and relationship capital, consisting in the contribution of the organisation to the society's well-being, the sharing of values and rules, the firm's intangible assets related to brand and reputation, and its social legitimacy to operate;

- natural capital, that is the environment (i.e. natural resources, biodiversity and eco-system health).

A capital's value changes consequently to business operations. For instance, financial capital increases when the firm obtains a loan, and it decreases when an equipment is bought and a training course for employees is carried out. However, these operations determine an increase in manufactured capital and human capital respectively: actually, there is a transformation of capitals.

The integrated report should inform about the process of value creation (or destruction) resulting from the use of capitals in business activities and their conversion into outputs (i.e. products, services, by-products and waste) and outcomes (i.e. effects on the capitals themselves): in other words, the integrated report should describe the virtuous circle connecting the use of resources, the development of activities and the obtainment of results, taking account of both the risks and the opportunities affecting the capitals, in order to prevent the former and to maximise the latter.

The <IR> process must respect the Guiding principles contained in Chapter 3: strategic focus and future orientation; connectivity of information; stakeholder relationships; materiality; conciseness; reliability and completeness; consistency and comparability.

First of all, an integrated report should be strategy-focused and future-oriented, so it should explain opportunities, risks and internal or external dependencies that can influence value creation over time.

For example, the Danish healthcare company Novo Nordisk states in its 2011 Report that "Novo Nordisk's business is focused on those therapy areas that leverage our distinct capabilities and strengths: developing and delivering superior protein analogues and the largescale manufacturing and global commercial infrastructure necessary to make these analogues widely available. [...] For those millions of people who live with diabetes, our goal is to offer treatment options that are safe and convenient so that they can live their lives to the fullest. [...] The primary intention of our research efforts in diabetes is to address the unmet medical need to safely and effectively lower blood glucose while reducing the risk of hypoglycaemia. As well as developing new-generation insulins, longer term we hope to radically change insulin delivery by offering tablets in addition to injectable treatments [...]".

(Source: Novo Nordisk, Annual Report 2011. Financial, social and environmental performance, pp. 18-19)

Connectivity of information requires a holistic representation of the firm's external environment, strategy, governance, opportunities and risks, resource combination, business activities, performance and future prospects. Connectivity of information is based on the association of different types of information: financial, 
social, environmental and market information; quantitative and qualitative information; past, present and future-oriented information; internal and external communications; data and descriptions contained in different reports. In this context, ICT can be useful to improve cross-reference and links among separate documents and sources of information.

The report of the Dutch insurance company Aegon NV contains an example of connectivity of information applied to the relationship among external environment, opportunities and risks, and strategy. With reference to the key trend summarised as 'A new working environment', the company states that "The workplace is changing rapidly. Increasingly, employees want to work for companies that share their values and offer real career prospects. The idea of a 'job for life' has almost disappeared, while new technology is changing attitudes and opening up new ways of working.

What are the opportunities? If we make the right changes, Aegon's workforce will become more flexible, more diverse and, ultimately, more effective. And we know that a more effective workforce will drive greater innovation and better service for our customers.

What are the risks for us? If we don't make these changes, Aegon risks losing its best employees - and failing to attract the new talent and new thinking that will drive our company forward".

(Source: Aegon, Helping make tomorrow, 2012 Review, p. 25)

The principle of stakeholder relationships requires the divulgation of information on the nature and quality of the relations between the firm and its key stakeholders, explaining in particular what the former does to consider and satisfy the legitimate expectations of the latter. This principle aims at enhancing the accountability of board members and managers as concerns the use of capitals they are responsible for, according to a mandate conferred by the firm's shareholders, a contract with external stakeholders or the social license to operate recognised by the community.

$\square$ For instance, the British bank HSBC provides a brief overview of how it interacts with each category of stakeholders: "[...] Customers. We serve 89 million customers in 85 countries and territories. We engage with our customers through a wide variety of channels, from written and electronic communications, to client events, customer panels and one-to-one meetings. Customer feedback is tracked across our businesses and drives our business development.

Shareholders. With listings on the London, Hong Kong, New York, Paris and Bermuda stock exchanges, shares in HSBC Holdings plc are held by over 220,000 shareholders. In 2011, HSBC ran a programme of 906 senior executive meetings with representatives of institutional shareholders in 27 countries and territories. We held also meetings with over 30 Sustainable and Responsible Investment institutional investors in London, Paris, Frankfurt, Boston and New York. [...]

NGOs. We engage with campaign groups on matters of shared interest. We are proactive members of a number of multistakeholder forums, such as the Roundtable on Sustainable Palm Oil, which brings 
together NGOs, businesses and financial investors to agree standards of good practice for the sector. [...]".

(Source: HSBC, Sustainability Report 2011, p. 7)

The principle of materiality imposes the disclosure of information on the matters that substantially influence the firm's ability to create value over time. Moreover, the Framework requires that the materiality determination process is explained in the integrated report.

An interesting example of the materiality determination process is provided in the sustainability report of the South Korean firm Hyundai: "Through the publication of the Sustainability Report for the last 2 years, Hyundai E\&C is undertaking sustainable management in the economic, environmental and social aspects. To determine the key issues per area to improve the sustainable management of Hyundai $E \& C$, the materiality of each issue was selected through a $3 \times 3$ matrix from the 'materiality for stakeholders' and 'materiality for Hyundai $E \& C$ ' perspectives. The materiality of issues was determined in accordance with the materiality analysis framework, which has been used for Hyundai E\&C since 2010. 18 key issues out of a total of 227 were selected, and the major reporting content was determined by the significance on these issues [...]".

(Source: Hyundai Engineering \& Construction, Sustainability Report 2012, pp. 8-9)

Even if an integrated report should provide all material information, it should be concise at the same time. To satisfy this principle, firms may use cross-references, links to external information, brief sentences, and plain language.

For example, the British leading retailer Marks \& Spencers employs the principle of conciseness in the opening part of its annual report, where it introduces its main KPIs. The firm also compares them with the plans and the previous years' results, providing exhibits and graphs.

The financial performance is measured by the following KPIs: Group revenue; underlying Group profit before tax; Group profit before tax; Group earnings per share underlying earnings per share; return on capital employed.

The competitive performance is summarised by the UK market share, average weekly footfall, percentage of population within a 30-minute drive of a full line store, multi-channel revenue, and international revenue.

The environmental performance is represented by greenhouse gas emissions.

(Source: Marks \& Spencer, Annual Report and Financial Statements 2013, p. 12-13)

Reliability and completeness should guide the whole $\langle\mathrm{IR}\rangle$ process, inspiring complete and impartial information on all the topics. Moreover, the report should apprise the users of internal controls on information and external and independent assurance. 
$\square$ The existence of external control on the report is underlined by Hyundai: "These selected issues and reporting content were confirmed by a third party verification institution for compliance with the 3 principles of AA1000AS: responsiveness, completion, and diversity”. (Source: Hyundai Engineering \& Construction, Sustainability Report 2012, p. 8)

The <IR> process should also respect the consistency and comparability principles: the reporting policies (such as the selection of KPIs) should not be changed from one year to the next, unless a modification could improve transparency. In fact, consistency gives the possibility to compare the contents over time. Comparisons among different firms can be also conducted when their integrated reports comply with the minimum requirements of the IIRC Framework.

Chapter 4 presents some questions each firm is expected to answer in order to disclose all the Content elements required by the Framework ${ }^{5}$. A general reporting guidance is also provided as an operational support to the organisations.

Firstly, the firm should explain what it does and under which circumstances it operates (organisational overview and external environment). The integrated report should clarify some introductory aspects, such as culture and values, ownership and operating structure, competitive environment and market positioning, with the possibility to use appropriate KPIs. This section should also refer to the external context and the significant factors affecting the firm, from different perspectives: legal, political, macroeconomic, commercial, social, demographic, environmental, technological, etc.

$\square$ Corporate values and culture drivers are stressed by the Brazilian company Natura as follows:

"The culture drivers were created based on our essence as a guide for our choices and mindsets. They are like tracks showing what we need to pay special attention to in our daily routines.

The creation of these drivers was the result of a process that involved the company founders, members of the executive committee and the leadership team. We also drew on reflections from the culture dialogues held with 150 employees from all levels of the administrative, operational and sales forces in 2009.

They are: commitment to the truth [...]; caring relations [...]; continuous improvement [...]; doing things well [...]; innovation [...]; sustainable development [...]; pleasure and joy [...]".

(Source: Natura, Report 2011, p. 4)

Then, the firm should describe its governance structure and its contribution to creating value over time. The main topics concern leadership, board composition and diversity, decision-making, ethical influence on the use of capitals, voluntary adoption of corporate governance best practices, remuneration systems and incentives linked to the use of (or changes in) the capitals.

$\square$ An example of corporate governance information is provided in the integrated report of Eskom, a South African state-owned electricity public utility:

“Eskom's corporate governance focuses on effective ethical leadership to integrate strategy, governance and sustainability. Eskom 
takes its strategic direction from its board of directors. The executive management committee is responsible for putting decisions made at board level into effect and overseeing the company's day-to-day operations".

Then, the report contains details on the board of directors and its internal committees; moreover it provides links to the corporate website for further information.

(Source: Eskom, Integrated Report 2012, p. 28 ff.)

After that, an integrated report is expected to clarify the organisation's business model. The document should pay attention to the main inputs, activities, outputs and outcomes, as well as to the dependencies on critical stakeholders. Firms with multiple business models - for example, one for each market segment - should describe all the material ones, their interdependencies and possible synergistic benefits.

$\square$ For instance, the business model of the Anglo-Dutch consumer goods company Unilever is introduced as follows:

"Our business model is designed to deliver sustainable growth. For us, sustainability is integral to how we do business. In a world where temperatures are rising, water is scarce, energy is expensive, sanitation is poor in many areas, and food supplies are uncertain and expensive, we have both a duty and an opportunity to address these issues in the way we do business.

The inputs to the model, like those of all major packaged goods manufacturers, are threefold: brands; people; and operations [...].

The outputs of the model are threefold: sustained growth; lower environmental impact; and positive social impact [...]".

(Source: Unilever, Annual Report and Accounts 2012, p. 9)

A specific section of the integrated report should disclose the sources of risks and opportunities affecting value creation over time, alongside with the methodologies of risk assessment and the response adopted, or at least planned, in order to protect the capitals. According to the materiality principle, the report should underline the risks with a high impact on the capitals, although their probability of occurrence is low.

A description of risks and risk responses is provided by Unilever as follows:

\begin{tabular}{|c|c|}
\hline Description of risk & What we are doing to manage the risk \\
\hline Systems and Information & \\
\hline $\begin{array}{l}\text { Unilever's operations are increasingly } \\
\text { dependent on IT systems and the } \\
\text { management of information. } \\
\text { We interact electronically with customers, } \\
\text { suppliers and consumers in ways which } \\
\text { place ever greater emphasis on the need } \\
\text { for secure and reliable IT systems and } \\
\text { infrastructure and careful management of } \\
\text { the information that is in our possession. } \\
\text { Disruption of our IT systems could inhibit }\end{array}$ & $\begin{array}{l}\text { Hardware that runs and manages core } \\
\text { operating data is fully backed up with } \\
\text { separate contingency systems to provide } \\
\text { real time back-up operations should they } \\
\text { ever be required. } \\
\text { We maintain a global system for the } \\
\text { control and reporting of access to our } \\
\text { critical IT systems. This is supported by an } \\
\text { annual programme of testing of access } \\
\text { controls. }\end{array}$ \\
\hline
\end{tabular}


our business operations in a number of ways, including disruption to sales, production and cash flows, ultimately impacting our results.

There is also a threat from unauthorised access and misuse of sensitive information. Unilever's information systems could be subject to unauthorised access which disrupts Unilever's business and/or leads to loss of assets. We have policies covering the protection of
both business and personal information, as
well as the use of IT systems and
applications by our employees. Our
employees are trained to understand these
requirements.
We have standardised ways of hosting
information on our public websites and
have systems in place to monitor
compliance with appropriate privacy laws
and regulations, and with our own
policies.

(Source: Unilever, Annual Report and Accounts 2012, p. 38)

Another section should focus on strategy and resource allocation to reach the established goals. Among the others, the report should describe the performance measurement system used by the firm, the influence of external environment on strategy and resource allocation, and the factors of competitive advantage. Furthermore, the report should explain how the key findings of stakeholder consultation are considered when strategic planning is carried out.

$\square$ For instance, the Crown Estate - a property owner governed by a British Parliament's act - presents its sustainability strategy and the four pillars it is based on: "tackling climate change and energy security [...]; driving environmental value [...]; sustaining communities [...]; working together [...]”.

For each pillar, the Crown Estate provides information on the approach adopted, targets, activities, investments, performance (compared with the targets), and next steps.

(Source: The Crown Estate, Building Strong Partnerships. Annual Report 2011, p. 45 ff.)

A section of the report should analyse the firm's performance, compared to the strategic objectives, and the effects on all the types of capital. In this regard, the IIRC suggests the combined use of qualitative explanation and quantitative measures (such as financial and non-financial KPIs, connected each other to clarify the relations among different capitals).

BNDES, the Brazilian state-owned development bank, offers an example of information on performance, where we can also observe how to connect details on environmental and financial results: "Migration to the Free Electric Power Market. The BNDES falls under the free power consumer category and in 2011 migrated to the Free Market. This change allowed for the purchase of energy originating entirely from renewable sources and also represented a reduction in electric power costs of approximately $12 \%$ per month". (Source: BNDES, Annual Report, 2011, p. 219)

Finally, an integrated report should provide a future outlook about the challenges and uncertainties the firm could face, and the possible consequences in terms of 
strategy development and performance. Forecasts, projections and KPIs' expected trend can help the report users understand the potential evolution.

For instance, Novo Nordisk's report contains forecasts of the economic impact of a 5\% movement in key invoicing currency during the next year:

\begin{tabular}{|l|c|c|}
\hline $\begin{array}{c}\text { Key invoicing } \\
\text { currency }\end{array}$ & $\begin{array}{c}\text { Annual impact on Novo Nordisk's } \\
\text { operating profit of a 5\% movement in } \\
\text { currency }\end{array}$ & $\begin{array}{c}\text { Hedging period } \\
\text { (months) }\end{array}$ \\
\hline$U S D$ & $D K K 775$ million & 11 \\
\hline$J P Y$ & $D K K 170$ million & 12 \\
\hline$C N Y$ & $D K K 100$ million & 12 \\
\hline$G B P$ & $D K K 75$ million & 11 \\
\hline
\end{tabular}

Source: Novo Nordisk, Annual Report 2011. Financial, social and environmental performance, p. 13

Chapter 4 also requires the organisation to disclose the basis for preparation and presentation of its integrated report: the firm should provide information about the materiality determination process, the reporting boundary and the significant frameworks and methods applied to quantify and evaluate material matters.

The final part of the Framework contains a general reporting guidance consisting in operating recommendations for implementing both the guiding principles and the content elements. Among other things, the Framework considers the characteristics of quantitative indicators, the distinction among short, medium and long term and the consequent production of quantitative and qualitative information, and aggregation or disaggregation of information.

\section{Strengths and Weaknesses of Integrated Reporting}

Integrated reporting is undoubtedly innovative, thanks to its principles-based approach and emphasis on different types of capitals, and it can produce various benefits for the firm. However, there are also some weak points that could hamper its adoption, so overcoming such weaknesses is a great challenge for improving stakeholder relations management.

Generally speaking, a valuable aspect of integrated reporting is its contribution to clarifying the relationships between financial and non-financial performance, which are sometimes underestimated by directors and managers. Carrying out an integrated reporting process requires the organisation to analyse how it concretely translates its strategy for long-term value creation into day-by-day operational activities, which should benefit (or could hurt) the stakeholders. For instance, a description of R\&D activities for the introduction of eco-friendly products - which generate higher costs and lower profits in the short term - can enhance the firm's reputation as a sustainable-oriented company, attract the attention of the ethical investment industry and increase the revenue in the medium and long term.

Another advantage consists in the improvement of risk management and measurement methodologies adopted by the firm. Indeed, explaining the 
relationships between financial and non-financial results encourages to identify a multitude of success key factors and correlated risk key factors, which usually refer to social and environmental aspects too. Hence, non-financial KPIs have to be built and used for behavioural orientation of the personnel, as well as to analyse, evaluate and disclose the performance actually achieved. Such a change in performance measurement systems can be effective in the presence of collaboration among different units or teams within the organisation, in order to define the most appropriate and understandable indicators.

Consequently, integrated reporting also stimulates a better comprehension and acceptance of the roles accomplished by each individual or unit in the process of value creation. Moreover, it highlights the opportunity of involving such people in decision-making and assessment processes.

Other benefits derive from the progressive emphasis on the use of an electronic format for the firm's disclosure. Within the corporate communication, the integrated report connects and coordinates different types of information. Indeed, the integrated report contains concise information on boards, procedures and results; for the collection of further details, the report refers to more specific documents divulged through the corporate website. Thanks to the Internet, the firm can also involve the report users in a review of the activities and performance represented in the document, as well as ask them to assess the reporting process and contents themselves: this is made possible by the web tools for discussion and feedback (e.g. e-mail, social forums and blogs).

Alongside with the benefits connected to organisational relationships, risk management, performance measurement, external disclosure, and stakeholder relations management, an integrated reporting process can also originate problems.

Considering the economic profile, the quantity and variety of information necessary for issuing an integrated report can determine a big increase of costs, if the information is not organised in the best way. From an organisational point of view, collecting, preparing and transferring a large amount of information on different topics require significant training and investment to improve the existing information system. Moreover, high complexity of communication could generate confusion for both the personnel and the external stakeholders, if the reporting process is not adequately carried out and periodically checked. In such a situation, the firm risks losing credibility and suffering reputational damages.

As specifically concerns the IIRC Framework, it openly considers the integrated report as primarily prepared for the providers of financial capital. This approach typically refers to the shareholder view and adopts a market-oriented perspective; so, it privileges the information needs of a well-identified category of stakeholders. However, this prevailingly shareholder-based nature is compensated by a comprehensive approach to corporate communication, which promotes the connection among different types of information; hence, the resulting report seems to be adequate to satisfy the knowledge needs of all other stakeholders too.

The model proposed in the Framework is innovative, but there is the risk that organisations meet difficulties in adopting the principles-based approach. A more detailed format could be more appropriate and effective: for example, a list of fundamental KPIs would help the organisations compose their own integrated reports and would provide the basic conditions for comparability among the reports. 
The suggested conciseness of a stand-alone integrated report is certainly functional for users looking for a comprehensive overview of the organisation; however, it appears too generic and abstract, and sometimes even contradictory. In fact, the assortment of information that should be included in the report makes it very difficult to comply with the principle of conciseness. The risk of redundancy and duplication of information is high, particularly for firms with multiple business models: the basic unity of governance determines the development of common elements that are shared by the different business models, so it could be hard not to duplicate information. Moreover, the integrated report suggested by the IIRC risks increasing the complexity of corporate communication, because it is not intended to replace any other mandatory or voluntary report.

The capital-based approach is probably the distinguishing feature of the Framework. However, applying such a model could be very ambitious in many organisations, particularly in SMEs, which are accustomed to classify their resources into only tangible and intangible assets, without introducing further categories. Even if the capital categorisation is not strictly imposed by the Framework, it constitutes the real innovation of this process, so the lack of one or more categories of capital would make the integrated report less useful. Moreover, many firms tend to overlook intangible resources management and interdependencies; hence, they would probably divulge many financial indicators together with prevailingly narrative explanations on intellectual, human, social and natural capitals. Summarising, the risk of unbalancing quantitative information on financial (and manufactured) capital and qualitative information on all the others is concrete.

The recommended transparency on the materiality determination process is appreciable: indeed, it is important to inform the stakeholders about the procedure used to prioritise matters through an assessment of magnitude and likelihood of occurrence. However, this process is partially subjective, particularly when it depends on qualitative factors.

Another significant element of the IIRC Framework refers to internal and external controls on the reporting process and the integrated report. More than anything, external and independent assurance seems to be the best mechanism for demonstrating the reliability of an integrated report, as recommended by the IIRC. However, the Framework is vague as concerns the concrete development of assurance engagement. In our view, the selected assurance provider could involve representatives of the stakeholders to gather their opinions on the increase, decrease and transformation of capitals described (and measured) by the firm: the existence of evidence of such variations from a stakeholder's point of view would prove the reliability of the report. Moreover, assurance should cover the integrated report as a whole: indeed, this approach is already used by assurance providers who certify sustainability reports. Anyway, if the complexity of an integrated report requires a variety of knowledge and skills for the assurance process, this could be managed by a mixed team comprising financial auditors and experts in social, intellectual capital and environmental reporting. Finally, the Framework does not identify the criteria for the most effective verification: in our opinion, those already defined by the international setters could be a good reference (for example, ISA for the audit of financial information, and ISAE 3000 and AA1000 Assurance Standard for the audit of social, environmental and sustainability reporting). 
Also the request of details on the linkage between remuneration policies and modifications in capitals in the short, medium and long term stimulates both appreciation and critics. Nowadays transparency on compensation systems is imposed all over the world, particularly to large companies. Unfortunately, we forecast that few firms will divulge such details in the absence of mandatory provisions. As a matter of fact, even listed companies tend to be very concise about their incentive criteria, which are often generically summarised as 'performancebased'.

\section{Emerging Issues Concerning Corporate Communication}

The advent of corporate sustainability principles and the recognition of strong connections among economic, competitive and socio-environmental factors have increasingly emphasised the importance of forms of external reporting supplementing the traditional financial statements and demonstrating the complexity of stakeholder relations.

In particular, academics and practitioners have taken an interest in the contents, updating and dissemination of corporate communication since the last decade of the twentieth century, in order to overcome the partiality of information that was typical of documents focalised on specific aspects of responsibility. In this regard, some reports promoting a continuous and effective analysis of corporate structures, processes and results have become more and more important. The integrated report is one of such documents.

An integrated report should be direct to all stakeholders and should permit them to evaluate the firm's governance structures and strategy, as well as the past, present and future performance concerning financial, social and environmental aspects. In other words, suitable information should be prepared to improve the firm's communication to stakeholders, by emphasising the basic conditions of unity, continuity and transparency.

Many organisations have worked on integrated reporting. Among the others, the International Integrated Reporting Council has aroused worldwide consensus and it is still playing a leading role in the debate through the development of a new reporting framework. Such initiative is expected to join the existent reporting standards to create a broadly shared, coherent and integrated informative structure.

The IIRC Pilot Programmes and the Framework of December 2013 are indicative of the commitment to an advanced concept of reporting, potentially aimed at enhancing the effectiveness of corporate communication.

As stated in the article, the Framework has a number of strengths, but it is not free from weaknesses: in particular, it is primarily intended to meet investors' needs of information rather than implement correct principles of stakeholder relations management.

The Framework represents a remarkable effort for the promotion and adoption of forms of integrated reporting based on universally shared principles, which assure strong comparability over space and time. The large involvement of firms, institutes, academics and practitioners in discussing, experimenting and perfecting the model induces to expect further refining from a perspective of transparency. 
However, the existence of a globally accepted reporting model does not assure the actual effectiveness of corporate disclosure. Indeed, this depends on the adoption of reliability and transparency logics in external communication. Such logics require a strong corporate culture, based on shared values of responsibility in behalf of all stakeholders and oriented to satisfy their needs of knowledge and evaluation; furthermore, they encourage participation and cooperation and guarantee information symmetry.

The introduction of internationally recognised models of integrated reporting definitely supports the improvement of corporate communication according to sustainable value creation. However, implementing such principles in different operational contexts requires that firms overcome opaque and reticent behaviour and avoid phenomena of information asymmetry which favour certain groups of dominant stakeholders.

More exactly, the integrated reporting model should be a guide for enhancing transparency and overcoming the gap among communication, perception and behaviour, among expectations and results, and among information for different users.

A number of scandals involving firms of industrialised countries have stressed the lack of a responsibility-oriented approach of corporate governance, based on a modern understanding of the interactions between the corporate success over time and the equitable composition of all stakeholders' interests. Specifically, firms are often characterised by divergence between formal commitment to sustainability and concrete behaviour: filling this gap is necessary to really achieve effectiveness and transparency in integrated reporting.

\section{Bibliography}

Brondoni S.M. (2006) Managerial Corporate Governance Communication, Symphonya. Emerging Issues in Management (symphonya.unimib.it), n. 1., pp. 8-23 http://dx.doi.org/10.4468/2006.1.02brondoni

Dierkes M. (1974) Die Sozialbilanz - Ein Gesellschaftsbezogenes Planungs-, Informations- und Rechnungssystem, Frankfurt, Herder \& Herder.

Eccles R.G., Krzus M.P. (2010) One Report. Integrated Reporting for a Sustainable Strategy, John Wiley \& Sons, Hoboken, New Jersey.

Eccles R.G., Serafeim G. (2011) Accelerating the Adoption of Integrated Reporting, in De Leo F., Vollbracht M. (eds.), CSR Index 2011, InnoVatio Publishing Ltd.

Epstein M., Flamholtz E.G., McDonough J.J. (1976) Corporate Social Accounting in the United States of America: State of the Art and Future Prospects. Accounting, Organizations and Society, pp. 23-42 http://dx.doi.org/10.1016/0361-3682(76)90005-2

European Commission (2013) Proposal for a Directive of the European Parliament and of the Council amending Council Directives 78/660/EEC and 83/349/EEC as regards disclosure of nonfinancial and diversity information by certain large companies and groups. Strasbourg, 16.4.2013, COM(2013) 207 final.

IIRC (2013), The International <IR > Framework, December.

Jensen J.C., Berg N. (2012) Determinants of Traditional Sustainability Reporting versus Integrated Reporting. An Institutional Approach. Business Strategy and the Environment, vol. 21, n. 5, pp. 299-316. DOI: http://dx.doi.org/10.1002/bse.740 
Krzus M.P. (2011) Integrated Reporting: If Not Now, When?, IRZ - Zeitschrift für International Rechnungslegung, n. 6, June, pp. 271-276.

Perrini F., Vurro C. (2010) Corporate Sustainability, Intangible Assets Accumulation and Competitive Advantage Constraints, Symphonya. Emerging Issues in Management (symphonya.unimib.it), n. 2, pp. 25-38 http://dx.doi.org/10.4468/2010.2.03perrini.vurro

Salvioni D.M. (2003) Corporate Governance and Global Responsibility, Symphonya. Emerging Issues in Management (symphonya.unimib.it), n. 1., pp. 44-54 http://dx.doi.org/10.4468/2003.1.05salvioni

Salvioni D.M. (1990) Economic Information in global corporate communication processes. Economia Aziendale, vol. IX.

Salvioni D.M., Bosetti L. (2009) Corporate Responsibility, Ethics and Management Control. Some evidence from Italian Public Utilities, in Frenkel D.A., Gerner-Beuerle C. (eds.), Challenges of the Law in a Permeable World, pp. 67-86, ATINER, Athens.

Solstice (2005) Integrated Reporting. Issues and Implications for Reporters, sponsored by Vancity.

\section{Notes}

${ }^{1}$ The Brundtland Report defined sustainable development as the one «that meets the needs of the present without compromising the ability of future generations to meet their own needs».

${ }^{2}$ For instance, the EU issued a White paper on environmental responsibility in 2000 and a Green paper on corporate social responsibility in 2001. Then, it promoted the establishment of the European Multistakeholder Forum on Corporate Social Responsibility (CSR) in 2002 and the CSR Alliance in 2006: these initiatives still involve firms, trade unions, NGOs and the civil society.

${ }^{3}$ GBS was formally constituted in 1998 as the Study Group for Establishing Social Reporting Standards. It involves universities, professional councils of chartered accountants and auditors, financial audit companies and other agencies and experts. In 2001 GBS published its first social reporting standards, which were followed by several research documents. Further details at http://www.gruppobilanciosociale.org/en/.

${ }^{4}$ The Italian Ministry of Labour officially started a project on CSR and social commitment in 2002, in reply to the EU Green paper issued the year before. The project encouraged Italian firms to publish a social report including a list of suggested KPIs on the relationships with different categories of stakeholders.

${ }^{5}$ Examples of topics to be handled in each answer are also provided by the IIRC. 